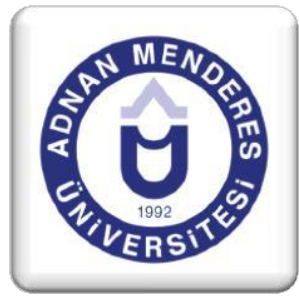

\title{
Haberin Küreselleşmesi: Kuramsal Bir Değerlendirme
}

\author{
SIBBEL FÜGAN VAROL ${ }^{1 *}$
}

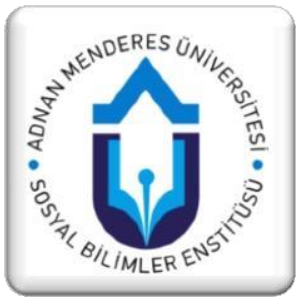

\section{ÖZET}

Haberin küreselleşme süreci uluslararası haber ajanslarının kurulduğu 19. yüzyıla kadar uzanmaktadır. Haberin üretim ve dağıtım sürecinin az sayıdaki uluslararası haber ajansının kontrolünde olması uluslararası haberlerde tektipleşmeye ve gelişmiş ülkelerden gelişmekte olan ülkelere doğru tek yanlı haber akışına yol açma, Batılı ülkelerin ulusal çıkarlarına hizmet etme, uluslararası kamuoyu gündemini belirleme gücüne sahip olma ve ülkeler arasındaki asimetrik güç ilişkilerini pekiştirerek medya emperyalizmi tezini haklı çıkarma gibi eleştirilere yol açmıştır. Bu eleştirilerin karşısında ise, yerli medya kuruluşlarının dış haberleri yerel izleyicilerin hassasiyet ve ilgilerine uyarlayarak yerelleştirdiği, günümüzde haberin yalnızca Batı'dan Doğu'ya ve Kuzey'den Güney'e tek yönlü olarak akmadığı, Al Jazeera gibi Batılı olmayan aktörlerin haber piyasasına girmesi sonucunda haberde karşı akışın da yaşandığı, dijital teknolojiler sayesinde haber tüketicilerinin alternatiflerinin arttığı ve elinde akıllı telefonu bulunan sıradan vatandaşların bile potansiyel muhabir haline geldiği, böylece çoğulcu bir ortamın oluştuğu görüşleri yer almaktadır. Tümü aynı bütünün farklı yönlerine işaret eden bu tartışmaların yeniden gündeme getirilmesi günümüzdeki haber coğrafyasının küresel arka planını anlamaya katkıda bulunmayı amaçlamaktadır.

Anahtar Kelimeler: Küresel haber, uluslararası haber ajansları, tektipleşme, yerelleştirme

\section{Globalization of News: A Theoretical Evaluation}

\begin{abstract}
Globalization of news dates back to the $19^{\text {th }}$ century. Concentration of news gathering and distribution process in the hands of few international news agencies is criticised for homogenisation of international news, one-way news flow from the developed countries to the developing countries, serving to the national interests of Western countries, having power to determine the international agenda and reinforcing the asymmetrical power relations between countries, thereby justifying the media imperialism thesis. However, there are some views opposing to these criticisms, claiming that the local media organisations domesticate international news to meet the tastes and interests of local audience, that today the global news does not flow in one-way from the West to the East and from the North to the South, instead there is a contra-flow thanks to the non-Western news actors like Al Jazeera, that digital technologies multiplied the news alternatives for news consumers and made each citizen with a smart phone a potential correspondent, thereby creating a pluralist news atmosphere. By reconsidering these views, each of which underlines a different part of the same whole, this article intends to provide an insight into the global background of the current news geography.
\end{abstract}

Keywords: Global news, international news agencies, homogenisation, domestication 


\section{Giriș}

Bilgi ve iletişim teknolojilerinde 20. yüzyılın ikinci yarısında yaşanan gelişmeler, dünyanın farklı noktalarına fiziksel veya elektronik olarak ulaşabilme olanağını ve hızını artmış, bu ise dünyanın farklı noktalarındaki olayların kısa bir süre içinde haberleştirilebilmesine imkân sağlamıştır. Haber akışının hızlanması, bir yandan haberin önemini ve etki gücünü artırırken, diğer yandan kitlelere ulaşan uluslararası haberin miktarını ve niteliğini değiştirmiştir. Bugün ulaşılan noktada, haber, Lisbeth Clausen'in (2010: 127) ifadesiyle, format1, içeriği ve tarzı dünya çapında kabul edilen "küresel bir olgu" haline gelmiştir.

Henüz "teorik inşa" sürecinde bulunan küresel haber kavramı, haber akışı çalışmalarındaki uluslararası ve yerel haber ikilemini aşmada faydalı olabilir. Çünkü artık haber medyasının giderek yersizyurtsuzlaştığı bir dünyada ulusal/uluslararası haber veya yerel/dış haber şeklindeki geleneksel ayrımları yapmak giderek zorlaşmaktadır (De Beer, 2010: 596). Küresel haber kavramı bu zorluğu aşmak üzere önerilse de, günümüzdeki gazetecilik pratiklerinde yaşanan asimetrik bağımlılık ilişkileri, kavramın sistem eleştirisiyle kodlanmasına ve Clausen'in (2003a: 87) işaret ettiği gibi, "tektip haber" eleştirisiyle birlikte düşünülmesine yol açmıştır. Peter Berglez (2011: 143) de küresel boyutu bulunan ve küresel süreçlere yerleşik haberlerin küresel haber niteliği taşıyacağını söylemiştir. Bu anlamıyla, küresel haber uzak yerlerde gerçekleşen olayların anlatıldığı dış haberden farklıdır. Zira dış haber yerel olanla dış dünya arasındaki mekân farklılığını sürdürürken küresel haber mekânsal yakınlık oluşturma eğilimindedir. Angèle Christin (2016: 214) ise gazetecilerin sınır ötesinden haber toplama, işleme ve yaymasının rutin bir faaliyet olduğunu, ancak internetle birlikte uluslararası enformasyon alışverişinin arttığını, iletişim araştırmacılarının da mevcut medya sisteminin niteliğini göstermek üzere "küresel haber" kavramını kullandıklarını söylemiştir.

$\mathrm{Bu}$ çalışmada da mevcut haber ekolojisinin niteliğini göstermek üzere, "küresel haber" kavramı üretim ve dağıtımı küresel medya kuruluşları tarafından gerçekleştirilen haber anlamında kullanılacaktır. Medya kuruluşlarının küreselleşmesi esas olarak 20. yüzyılın son çeyreğinden itibaren birçok ülkede yaşanan deregülasyon ve özelleştirme uygulamalarıyla gerçekleşse de, küresel haber ajanslarının ortaya çıkışı 19. yüzyıla kadar uzanmaktadır. Dolayısıyla, haberin küreselleşme sürecinin haber ajanslarının sahiplik yapısı ve haber üretim-dağıtım süreçleri açısından diğer medya kuruluşlarının küreselleşme sürecini öncelediği söylenebilir. Dijital teknolojilerde yaşanan gelişmeler haber üretim ve dağıtımını hızlandırmış ve yaygınlaştırmışsa da bu durum uluslararası haber akışındaki dengesizliği ortadan kaldırmamıştır.

Uluslararası haber akışındaki dengesizlikler yarım yüzyılı aşkın bir süredir iletişim alanındaki önemli tartışma başlıklarından birini oluşturmuştur. Bu tartışmaların yeniden gündeme getirilmesinin günümüzdeki küresel haber sistemini anlamaya katkıda bulunacağ varsayımından çıkan bu çalışmada da haberin küreselleşme sürecinin ortaya çıkardığı sonuçların neler olduğu sorusuna yanıt bulunması amaçlanmıştır. Kaynak taraması yöntemiyle yapılan çalışma kapsamında, öncelikle haberin küreselleşme sürecinin nasıl gerçekleştiği ortaya konulmuş, daha sonra, haberin küreselleşmesinin sonuçları tektipleşme, haber akışında dengesizlik, haberlerin Batılı ülkelerin gözünden sunulması, medya emperyalizmi gibi eleştirel yaklaşımlar ve yerelleştirme, karşı akış, haber çeşitliliğinin artması gibi iyimser yaklaşımlar temelinde tartışılmıştır. 


\section{Haberin Küreselleșme Süreci}

Küresel haber ağlarının en önemli aktörleri uluslararası haber ajanslarıdır. Haber üretimi ve dağıtımının maliyetli yapısı ve yerel medya kuruluşlarının dünyanın her yerinde muhabir bulunduramayacak olması, uluslararası haberlerin toplanma ve dağıtım süreçlerinin uluslararası haber ajanslarının kontrolüne girmesine yol açmıştır. Bu dengesizlik yeni ortaya çıkan bir durum olmayıp uluslararası haber ajanslarının yaklaşık 150 yıllık tarihinin mirasidır.

İlk haber ajans1, 1835 'te Charles Havas tarafından kurulan ve AFP'nin öncülü niteliğgindeki Havas Agency'dir. Daha sonra, 1849'da Alman haber ajansı Wolff ve 1851 yılında İngiliz haber ajansı Reuters kurulmuştur. Tümü Avrupalı olan bu kuruluşlar faaliyetlerine uluslararası ölçekte başlamıştır. 1848 yılında kurulan ABD'li haber ajansı Associated Press (AP) ise ancak bir sonraki yüzyılda uluslararası haber ajansı olarak faaliyet gösterebilmiştir (Mattelart, 1994: 15; Thompson, 2008: 235). Dolayısıyla, Birinci Dünya Savaşı'nın sonuna kadar uluslararası rekabet esas olarak Havas, Reuters ve Wolff arasında yaşanmıştır.

1850'li yıllarda Reuters, Havas ve Wolff arasındaki rekabet artmış ve onlar da rekabetin zararlarından kaçınmak için dünyayı aralarında özel çalışma bölgelerine ayırmaya karar vermiştir. 1869'da imzalanan Ajans Birliği Anlaşması'yla Reuters'e Britanya İmparatorluğu ve Uzak Doğu'da, Havas'a Fransız İmparatorluğu, İtalya, İspanya ve Portekiz'de, Wolffa ise Almanya, Avusturya, İskandinavya ve Rus topraklarında özel çalışma ayrıcalığı tanınmıştır. Bu üçlü ajans karteli, Birinci Dünya Savaşı'nın başlamasına kadar uluslararası haber toplama ve dağıtımına egemen olmuştur (Thompson, 2008: 235-6).

Görüldüğü üzere, dönemin üç büyük uluslararası haber ajansının faaliyet bölgeleri aynı zamanda ait oldukları ülkelerin ekonomik ve siyasi nüfuz alanlarıdır. Tümü Batı Avrupa'da yer alan bu ülkeler aynı zamanda dönemin sömürgeci güçleridir. Boyd-Barrett'in (aktaran Thussu, 2002: 21) işaret ettiği gibi, bu ajansların Avrupa dışındaki yayılmaları kendi devletlerinin 19. yüzyıl sonlarındaki karasal sömürgeciliğiyle yakından bağlantılıdır.

Birinci Dünya Savaşı'ndan sonra ise, ABD'nin süper güç konumuna yükselişine paralel olarak, Amerikalı haber ajansları Associated Press (AP) ve United Press International (UPI) küresel haber piyasasının önemli aktörleri haline gelmiştir (Magder, 2003: 32). Böylece, 1930'lara kadar üçlü ajans karteli fiilen sona ermiş, 1934'te Reuters ile AP arasında imzalanan anlaşmayla Amerikan ajanslarına dünyadaki haberleri serbestçe toplama ve dağıtma imkânı tanınmıştır. Amerikan ajanslarının hızlı büyümesine ve Reuters'in küresel pazarda güçlü konumunun devam etmesine karşın, diğer Avrupa ajansları büyük değişim geçirmiş, Fransa'nın 1940'ta işgal edilmesi Havas'ın dağılmasına ve yerini yeni bir ajans olan Agence France-Press'e (AFP) bırakmasına yol açmıştır. Nazizmin yükselişi, İkinci Dünya Savaşı'nda Almanya'nın yenilmesi ve ardından bölünmesiyle birlikte Wolf ajansı da uluslararası camiadaki nüfuzunu kaybetmiş ve sonunda kapanmıştır (Thompson, 2008: 2367).

İkinci Dünya Savaşı'nı takip eden birkaç on yıl "serbest enformasyon akışı" konusunda yoğun tartışmaların yaşandığı yıllardır. 1960'lı yıllarda çok sayıda sömürgenin bağımsızlığını kazanması, bu ülkelerin ulusal egemenliklerinin yalnızca politik söylemde değil, ekonomik ve kültürel olarak da tanınması talebini ortaya çıkarmıştır. Aynı yıllarda, Batı egemenliğinden kaynaklanan enformasyon dengesizliğine karşı politik bir hareket başlatılmıştır. Bağlantısız ülkeler, ajans haberlerinin politik etki yapmayı amaçladığını iddia etmiş ve kendi haber ajanslarını kurarak Batı medyasını dengelemeye çalışmıştır. Bu ajansların en önemlisi 1964 yılında kurulan Inter Press Service'tir. Dünyanın bir çok yerindeki büroları üzerinden Batılı haber ajanslarıyla rekabet etmeyi amaçlayan bu haber 
ajans1, haberlerde çeşitliliği sağlayacak nitelikte gazeteciler çalıştırarak haberin tektipleşmesine direnmiştir. Ancak, gerek Inter Press Services'in gerekse bu tür diğer haber ajanslarının başarısı sınırlı kalmıştır (MacGregor, 2013: 43).

1970'li yılların sonlarında, Batılı haber ajanslarının uluslararası haber akışındaki egemenliğine karşı tartışmaların adresi UNESCO olmuştur. 1980'de UNESCO tarafindan yayınlanan ve MacBride Raporu olarak da bilinen Many Voices, One World (Birçok Ses, Bir Tek Dünya) adlı raporda, enformasyon akışında az gelişmiş ve gelişmekte olan ülkeler aleyhine bir dengesizliğin bulunduğuna ve bu dengesizliğin giderilmesinin önemine dikkat çekilmiştir. Aynı raporda Yeni Dünya Enformasyon ve İletişim Düzeni'nin (NWICO) temel felsefesi ortaya konarak enformasyon akışı kalıplarında reform yapılması istenmiştir. Fakat talep eden yazarların istedikleri anlamda yeni bir uluslararası enformasyon düzeni kurulamamış, birkaç yıl sonra tartışma uluslararası gündemdeki yerini kaybetmiştir (Carlsson, 2003: 31).

Aradan geçen 30 yılı aşkın sürede bilgi ve iletişim teknolojilerinde yaşanan gelişmelerin haber akışını kolaylaştırması az gelişmiş ve gelişmekte olan ülkelerden gelen haber miktarını artırmışsa da, bu dengesizliğin Batı merkezli uluslararası haber ajansları lehine devam ettiğini söylemek mümkündür. Uluslararası haber akışı hala Batı merkezli az sayıda haber ajansının kontrolündedir. Dahası bilgi ve iletişim teknolojilerindeki gelişmeler ve aynı dönemde medya sektöründe yaşanan deregülasyon ve özelleştirme uygulamaları da büyük haber ajansları lehine işlemiştir. Chris Paterson'un (2007: 60) ifadesiyle, küresel toptan haber satış sistemindeki sahiplik yapısında yaşanan yoğunlaşma, küresel haber ajanslarının etkisini daha da artırmış ve sonuçta, New York merkezli AP ve (2008'de Thomson Corporation tarafindan satın alınıp ismine Thomson eklenen) Londra merkezli Thomson-Reuters dünyanın en büyük iki haber ajansı haline gelmiştir. Bu haber ajansları, BBC, CNNI, World Service Television (WSTV), ABC, CBS, NBC ve Fox gibi uluslararası yayıncılarla birlikte haber toplama ve dağıtımında dünyadaki yerli yayın kuruluşlarıyla kapsamlı bağlantılar kurmuş bulunmaktadır (Clausen, 2010: 130). Dolayısıyla, yaşanan gelişmeler haber ajanslarının farklı kaynaklardan beslenme imkânlarını artırmışsa da, gelinen noktada, uluslararası haber toplama ve dağıtımının kontrolü hala Batı merkezli büyük haber ajanslarının elinde bulunmaktadır.

\section{Haberin Küreselleşmesinin Sonuçları}

Uluslararası haber toplama ve dağıtım süreçlerinin az sayıda haber ajansının kontrolüne girmesinin sonuçları gerek UNESCO gibi uluslararası örgütler nezdinde, gerekse iletişim çalışmalarında önemli tartışmalara yol açmıştır. Bu tartışmaların ekseninde, medyanın küreselleşmesinin haber akışındaki dengesizliği artırdığı, tektip haberlerin tüm dünyaya yayılmasına yol açtığı, dünyaya yayılan haberlerin ise Batılı ülkelerin bakış açısıyla sunulduğu gibi eleştiriler yer almaktadır. Bu kötümser yaklaşıma karşın, bazı araştırmacılar, medya kuruluşlarının kendi ulusal çıkarlarına ve yerel izleyicilere hizmet edebilmek amacıyla dış haberleri yerelleştirdiğini, bilgi ve iletişim teknolojilerinde yaşanan gelişmelerin küresel haberin çeşitlenmesine yol açtığını, haber üretim ve dağıtımının oligopol yapısına karşı alternatif medya kuruluşlarının ortaya çıktığını iddia etmiştir. 


\subsection{Eleştirel Yaklaşımlar \\ 3.1.1. Haberlerin tektipleșmesi}

Küresel haber sistemi, yerli haber kuruluşlarının haber içeriklerinde az sayıda uluslararası haber ajansına bağımlı olduğu bir yapıya sahiptir. Bu yapı, benzer haberlerin uluslararası haber ajanslarından dünyaya yayıldığ 1 ve haberde çeşitliliği ortadan kaldırdığı gerekçesiyle eleştirilmektedir.

Ulusal medya kuruluşlarının, Clausen'in (2003b: 106) deyimiyle, yalnızca gelen haber içeriklerini seçen veya reddeden eşik bekçileri olarak hareket ettiği küresel haber sisteminin uluslararası haberlerde tektipleşmeye yol açan unsurlarından biri, uluslararası haber ajanslarının kendi aralarındaki bağlantılardır. Bu bağlantılar, Daya Kishan Thussu'ya (2002: 163) göre, özellikle Anglo-Amerikan haber kuruluşları arasında yoğun olarak yaşanmaktadır. Aralarındaki siyasi, kültürel yakınlık ve dil ortaklığı enformasyonu, görselleri ve hatta gazetecileri paylaşmalarına yol açmaktadır. Bu doğrultuda, CNN'de bir ITN raporunu veya $\mathrm{BBC}$ haberlerinde bir CNN görselini görmek olağan dış1 bir durum değildir. Örneğin, 19541993 yılları arasındaki 40 yıl boyunca, NBC, haber fotoğraflarını BBC'yle paylaşacak bir düzenlemeye sahip olmuştur.

Uluslararası haberlerin benzeşmesinin bir diğer nedeni ise haber ajansları arasındaki rekabet baskısıdır. Paterson'un (1998'den aktaran Clausen, 2010: 130) ifadesiyle, bu bask1, haber ajanslarını birbirlerine verdikleri haber içeriklerini kopyalamaya yöneltmektedir. Bu durum, haber kaynağı, haber değerleri ve gazetecilik rutinleri açısından uluslararası haber ajansları arasındaki benzerliklerle ve haberlerin çerçevesi veya içerdiği temalardaki benzeşmeyle birleşince uluslararası haberlerin belli düzeyde tektipleşmesine neden olmakta ve haber çeşitliliğini azaltmaktadır.

Haberin çeşitliliğini tehdit eden bir diğer önemli unsur, uluslararası haber ajanslarının birçok haberi ortaklaşa hazırlaması anlamına gelen sendikasyon uygulamalarıdır. Bu şekilde hazırlanan haberler yerli haber kuruluşları tarafından çoğu kez alındığı haliyle kullanılmaktadır. Araştırmalar, haber içeriklerinin Avustralya'da \%65'inin, İngiltere'de $\% 70$ 'inin, Almanya'da ise \%80'e kadar olan kısmının ajans haberlerinin kopyası olduğunu tespit etmiştir. Özellikle internet gazetelerindeki "son dakika" haberlerinin \%80-90'1 haber ajanslarından geldiği haliyle ve herhangi bir revizyona uğramadan kullanılmaktadır (Matthews, 2013: 246).

İnternet gazeteciliği de haberin çeşitlenmesine katkıda bulunmaktan çok tektip haberlerin dünya üzerinde kolayca yayılmasına imkân sağlayarak haberin tektipleşme sürecine katkıda bulunmuştur. Phil MacGregor'un (2013: 44) deyişiyle, ticari haber siteleri ajanslardan aldıkları haberleri kendi etiketlerini ve web tasarımlarını kullanarak, fakat içeriklerini değiştirmeden kullanmakta, böylece uluslararası haber ajanslarına ücret ödeme yükümlülüğünden kurtulmaktadır. Böylece, holding çıkarlarını kamu çıkarlarının önüne koyan ve reformcu sesleri marjinalleştiren, dolayısıyla mevcut küresel çıkarları güçlendiren sistem kendini devam ettirmektedir.

\subsubsection{Haber akışında dengesizlik}

Dünyada, gelişmiş ülkelerden gelişmekte olan ülkelere doğru dengesiz bir haber akışı vardır. Uluslararası haberlerin çoğu, merkezi ABD, İngiltere, Fransa gibi Batı ülkelerinde yerleşik haber ajansları tarafindan üretilmekte ve dağıtılmaktadır. Bu durum, haber toplama pratiklerinin büyük ölçüde gelişmiş ülkelerde gerçekleşmesine, dolayısıyla haber akışının ağırlıklı olarak gelişmiş Kuzey ülkelerinden gelişmekte olan Güney ülkelerine doğru yaşanmasına yol açmaktadır. Gelişmekte olan ülkelerin kendilerine ait haber dağıtım 
mekanizmasının olmaması veya sınırlı olması ve başka ülkelerde haber toplama maliyetinin yüksekliği nedeniyle aksi yönde haber akışı cılız kalmaktadır.

Küresel haber dağıtım sistemindeki tek yönlü akış, tüm dünyanın gelişmekte olan ülkelerdeki haberleri uluslararası medya kuruluşlarının düzenlediği ş̧ekliyle öğrenmesi anlamına gelmektedir. Mevcut durumda, gelişmekte olan ülkeler komşuları, kendi durumlarındaki diğer ülkeler ve hatta zaman zaman kendilerine ilişkin gelişmeleri de yine gelişmiş ülkelerin egemenliğindeki küresel haber ağlarından ve onların süzgecinden geçmiş haliyle öğrenmektedir. Diyelim komşu bir ülkeden gelen haberler yerel bir ajans raporunda toplanmakta, gelişmiş ülkedeki merkez ofise gönderilmekte, oradan da yeniden gelişmekte olan ülkelere iletilmektedir (Sparks, 2007: 102).

Tek yönlü ve dengesiz haber akışına ilişkin tartışmalarda eleştirilen konulardan biri de farklı ülkelerde dünyanın geri kalanına yönelik dengesiz ilgi seviyeleri bulunmasıdır. Çevre ülkelerdeki medya sistemlerinin merkez ülkeler tarafindan kontrol edilmesi, merkez ülkelerdeki olay ve sorunların daha yoğun olarak haberleştirilmesine yol açmaktadır. Uluslararası haber ajansları da iç savaş, doğal afet, açlık veya sansasyonel olaylar söz konusu olmadıkça Güney'den gelen haberleri göz ardı etmekte, Afrika, Latin Amerika veya Asya'nın yoksul bölgelerindeki olumlu gelişmeleri haberleştirmemektedir. Bunun sonucunda, çevre ülkelerindeki izleyiciler uluslararası haber medyasını yerel haber medyasından daha çok tercih etmekte, yerel medyadaki eşik bekçileri de bu tercihlere uygun olarak hareket etmektedir. Örneğin çoğu kez ABD'de veya İngiltere'de meydana gelen olaylar üçüncü dünya ülkelerinde yaygın bir şekilde öğrenilirken, üçüncü dünyada yaşanan olaylar ABD veya İngiltere'de pek bilinmemektedir. Dolayısıyla, küresel habercilik, Monica Lewinsky veya O. J. Simpson gibi Amerikan hikâyeleri bütün dünyada bilinirken üçüncü dünya ülkelerinde yaşanan gelişmelerin ABD'de duyulmaması anlamına gelmektedir (Archetti, 2008: 464; Herbert 2001: 19, 59; McPhail, 2006: 175). Bu ise, Batılı ülkelerde yaşanan gündelik veya özel olayların bile diğer ülkelerde yaşanan olaylardan, dolayısıyla Batılı ülkelerin diğer ülkelerden daha önemli olarak gösterilmesi anlamına gelmektedir.

\subsubsection{Haberlerin Batılı ülkelerin gözünden sunulması}

Uluslararası haberlerin tek yönlü akışı, Batılı haber ajanslarının, gelişmiş ülkelerin çıkarları doğrultusunda genel bir "Batılı" yanlılık sergilediği eleştirilerini ortaya çıkarmıştır. Bu eleştirilere göre, söz konusu asimetrik haber akışı üzerinden Batı kültürü yoğun olarak empoze edilmekte, bu ise gelişmekte olan ülkelerdeki kitlelerin Batılı normları ve materyal arzuları benimsemesine yol açmaktadır (MacGregor, 2013: 43; Boyd-Barrett, 1982'den aktaran Ryabinska, 2012: 2).

Batı merkezli tek yönlü haber akışının etkisi kültürel alanla sınırlı değildir. Haberin siyasi gücü dikkate alındığında, uluslararası haberlerin de uluslararası siyasi ilişkilerden bağımsız olduğunun düşünülemeyeceği açıktır. Şule Y. Özmen'in (2013: 132) ifadesiyle, dış haberler ve uluslararası habercilik aynı zamanda dış politika ve uluslararası politika kavramlarıyla yakından ilgilidir. Öte yandan, konu dış haberler ve uluslararası habercilik olunca tarafsızlık geçerliliğini yitirmektedir. Gazeteciler genellikle uluslararası arenada kendi ulusal çıkarlarına aykırı konuları haber olarak görmemektedir.

Küresel haberin az sayıda Batılı haber ajansından dünyanın geri kalanına büyük oranda tek yönlü olarak akması, Batılı ülkelerin siyasi ve ekonomik çıkarlarının küresel ölçekte desteklenmesi anlamına gelmektedir. Dahası, küresel haberi kontrolünde tutan uluslararası haber ajansları aynı zamanda ulusal haber ajanslarıdır. Colin Sparks'ın (2007: 101) işaret ettiği üzere, AFP, UPI ve AP'nin tümü ulusal haber ajansları olarak çalışmaktadır ve genel konulu haberlerdeki en büyük pazarları yine kendi ülkeleridir. Diğerlerinden farklı olarak 
Reuters ulusal haber ajansı olarak çalışmamaktadır ve rakiplerine nazaran daha fazla uluslararası müşteriye sahiptir. Fakat Reuters'ın da ülke bazında en büyük pazarı hala İngiltere'dir. Bu ise, MacGregor'a (2013: 39) göre, söz konusu haber ajanslarının kendi ülkelerinin çıkarlarından bağımsız davranamayacaklarının önemli bir göstergesidir. $\mathrm{Bu}$ doğrultuda, AFP, ilk dönemlerinde açıkça Fransa'nın çıkarları için propaganda yapmış, Reuters İngiltere yanlısı bir tutum izlemiş, AP de ait olduğu gazetelerin etkisi altında hareket etmiştir.

Uluslararası haber akışındaki Batı yanlısı tutum, daha haber toplama pratiklerinde başlamaktadır. Bir ülkede haber toplayan yabancı muhabirler, haberleştirdikleri olaylara ilişkin derin bir kültürel kavrayışa sahip olmak bir yana, daha yerel dili bile bilmemektedir. Olayları derinlemesine kavramadan yapılan haberler için kullanılan rehber ise Batı perspektifi olmaktadır. Zira büyük haber ajanslarında çalışan gazetecilerin üçte ikisinden fazlası Amerikalı ya da Avrupalıdır ve dünyaya kendi ülkelerinin perspektifiyle bakmaktadır. Günlük gazetelerin en deneyimli yurtdış1 muhabirleri bile ajansların gücüne karş1 koyamamakta, kendi derledikleri dış kaynaklı bir haberi ülkelerindeki yazı işlerine kabul ettirmeyi çok azı başarabilmektedir (Clausen, 2010: 132; Schneider ve Raue, 2000'den aktaran Öztürk, 2013: 24). Ayrıca, Paterson'ın (2006: 60, 61) dediği gibi, haber ajansları, farklı ülkelerdeki haber editörlerini memnun etmek zorunda olduğu için, nesnellik ve tarafsızlık görünümü yaratmak istemekte, bunu yaparken de dünyanın yavan, homojen, fakat hala ideolojik olarak belirgin bir resmini oluşturmaktadır. Dünya sahnesindeki egemen siyasi aktörlerin ideolojik konumlarına karşı çıkan haberlerse yeterince ilgi çekmemektedir.

Uluslararası haber ajanslarının ülke aidiyeti haber değerlerine yaklaşımlarında da kendini göstermektedir. Diğer medya kuruluşları gibi uluslararası haber ajansları da haberleştirecekleri olay veya öyküleri seçerken belli haber değerlerine göre hareket etmektedir. Haber seçme sürecinde uygulanan haber değerleri ise habercinin ülke aidiyetinden bağımsız düşünülemez. Zira Hillel Nossek'in (2004: 346) ifadesiyle, haber değerleri kültürel-yerel çevreden bağımsız değildir. Gazetecilerin yerel bakış açıları ise mesleki norm ve değerlendirmelerinin ayrılmaz bir parçasıdır. Bir olayın haber değeri taşıyıp taşımadığını belirleyen, haberi çerçeveleyen ve içerdiği temaları seçen gazeteci haberi belli bir bakış açısıyla kurmaktadır. $\mathrm{Bu}$ anlamıyla, haber gazetecinin perspektifini yansıtır. Küresel haberlerin üretim ve dağıtım süreçlerinin ağırlıklı olarak Batılı gazetecilerin kontrolünde olması, o haberlerin Batı perspektifini yansıtacak şekilde seçilmiş, çerçevelenmiş ve düzenlenmiş olması anlamına gelmektedir.

\subsubsection{Uluslararası haber gündeminin belirlenmesi}

Maxwell E. McCombs ve Donald L. Shaw (1972, 1993'den aktaran McQuail, 2010: 512) tarafından geliştirilen "gündem belirleme" tezi, medyanın bir konuya yaptığı vurguyla kamuoyunun o konuya verdiği önem arasında bir bağlantı olduğu ve medyanın insanlara "nasıl" değil, fakat "ne hakkında" düşüneceklerini belirleme gücünün bulunduğu iddiasına dayanmaktadır. Medyanın bir olaya verdiği önemle, politikacıların ve halkın verdiği önem arasında bir bağlantı olduğunu gösteren kanıtlar bulunmuştur.

McCombs ve Shaw'dan sonra yapılan birçok araştırmada (örneğin, Musa, 1990; Rafeeq, 2007; Rosenthal, 2015; Wanta, Golan\&Lee, 2004), medyanın gündem belirleme işlevinin kültür ve dil farklılıklarına ve farklı medya sistemlerine rağmen uluslararası düzeyde de benzer şekilde işlediği tespit edilmiştir. Uluslararası kamuoyunun gündemini belirlemede en etkili medya kuruluşları ise ulusal medyanın dış haber kaynağını oluşturan uluslararası haber ajanslarıdır. Uluslararası haber ajansları haber seçme, çerçeveleme ve dağıtım süreçlerindeki etkin rolleriyle uluslararası haber gündemini önemli ölçüde etkilemektedir. Ulusal haber 
kuruluşları, "eşik bekçileri" olarak hareket ediyor olsa da, yaptıkları seçimler ancak onlara gönderilen haberler arasında olmakta, dolayısıyla, uluslararası haber ajansları tarafindan sınırları çizilmiş bir gündem onları da etkilemektedir.

AP, Thomson Reuters ve AFP gibi uluslararası haber ajanslarının haber gündemini belirlemesi, müş̧erilerine gönderdikleri yazılı, görüntülü ve sesli enformasyonun nitelik ve miktarının seçiminde kendini göstermektedir. Televizyon haberleri durumunda, yerli yayıncılar kendi haberlerini gönderilen videolar temelinde hazırlamakta, görüntüsü verilmeyen haberleri genellikle kullanmamakta ya da çok az kullanmaktadır (Paterson, 2001: 84). Ayrıca, haber ajanslarının gönderdiği materyallerin yerel editörleri etkilediği ve gazetelerde gündem belirleme etkisi yarattığ ${ }_{1}$ tespit edilmiştir. Haber ajansları belli bir konuyu kapsamlı olarak ele aldığında, gazete editörleri aynı konuda kendi haberlerini yapmak için gazeteci göndermeye daha eğilimli olmaktadır. (Watanabe, 2012).

Uluslararası haber ajanslarının gündem yaratma etkisinin politik sonuçları da bulunmaktadır. $\mathrm{Bu}$ ajanslardan alınan haberler yalnızca tek tek bireylerin değil, hükümetlerin, politikacıların, finans kuruluşlarının, yatırımcıların ve diğer önemli aktörlerin gündemini de belirlemektedir. Bu noktada Özmen'in işaret ettiği bir tehlike ortaya çıkmaktadır. Özmen'e (2013: 130) göre, haberin uluslararası alanda dolaşımının manipülasyondan uzak olması zordur. Örneğin, siyasi bir haber durumunda, haber kaynağının kendi siyasal çıkarları dışında açıklama yapması beklenemez. Bu haberin uluslararası niteliği varsa, haberi hazırlayan medya kuruluşu veya medya profesyonelleri kendi ülke çıkarlarına uygun hareket edecektir. Bir politikacının beyanatının dünya kamuoyu üzerindeki etkisi o beyanatın bir medya kuruluşu tarafindan haber olarak sunulduğunda yarattığı etkiden farklı olacak, profesyonel medya kuruluşlarının yaydığı haberler ve kurgulanmış mesajlar dünya kamuoyunu daha kolay etkileyecektir.

\subsubsection{Medya emperyalizmi}

Uluslararası haber ajanslarının küresel haber sistemindeki hâkimiyeti 1970'lerin medya emperyalizmi tezini doğrular niteliktedir. Medya emperyalizmi kavramı, "herhangi bir ülkedeki medya sahipliği, yapısı ve içerik dağıtımından herhangi birinin veya tümünün başka ülke veya ülkelerin medya çıkarlarının dış baskısına önemli ölçüde maruz kaldığı ve etkilenen ülkenin orantılı bir karşı etkisinin olmadığı süreç" (Boyd-Barrett, 1977'den aktaran van Elteren, 2014: 401) şeklinde tanımlanmaktadır. İletişim çalışmalarında ekonomi politik geleneğinden araştırmacıların (örneğin Boyd-Barrett, 1977; Herman\&McChesney, 1997; Schiller, 1991) geliştirdiği medya emperyalizmi tezi, medya kuruluşlarının sahipliği ve medya ürünlerinin dağıtımı konusunda merkez ve çevre ülkeler arasındaki dengesizliğin sorgulanmasına dayanmaktadır. Bu teze göre, medyanın yapısında ve rolünde gözlemlenen çeşitli kalıplar ABD ve diğer birkaç gelişmiş ülkenin medyaya kendilerine avantaj yaratacak şekilde egemen olduğunu göstermekte, uluslararası enformasyon akışı ise sömürge ilişkileri üretmektedir.

Kültür emperyalizminin bir alt kümesi olarak kabul edilen medya emperyalizmi tezi, ilk ortaya atıldığı yıllarda çevre ülkeleri arasında daha adil enformasyon alışverişine yönelik bir hareketin kavramsal çıkış noktasını oluşturmuştur. UNESCO kapsamındaki tartışmalarda NWICO kararının alınmasına kadar uzanan bu hareket, küresel medya akışındaki dengesizliğin giderilmesini talep etmiş ve her ülkenin dünya kamuoyunu kendi çıkarları, istekleri ve sosyo-kültürel değerleri hakkında bilgilendirme hakkına saygı duyulmasını istemiştir (Thussu, 2002: 47). Öte yandan, postmodern teorilerin yükselişi, ABD ve İngiltere hükümetlerinin 1980'lerden sonraki neoliberal söyleminin benimsenmesi ve 1970'lerdeki hâkim modern söylemin bir parçası sayılan büyük anlatıların gözden düşüşü medya 
emperyalizmi tezinin de gözden düşmesine neden olmuştur (Matos, 2012). Artık, haber yayıncılığıyla ilgili olarak "medya emperyalizmi" yaklaşımının bugünkü uluslararası durumu gerçekçi bir şekilde yansıtmadığı, zira 90'lardan bu yana farklı bölgelerde medya pazarlarının ortaya çıktığı iddiası yaygın kabul görmektedir. Bugün daha az duygusal terimlerle konuşulmakta, emperyalizm teriminin yerine haber veya enformasyon akışı ve karş1-akış gibi terimler kullanılmaktadır (MacGregor, 2013: 43).

Medya emperyalizmi tezi gözden düşmüş olsa da, emperyalizm kavramının ülkeler arasındaki güç ilişkilerindeki dengesizliğe işaret etmesi nedeniyle, medya emperyalizmi kavramının haber üretim ve dağıtım süreçlerindeki uluslararası asimetrik güç ilişkilerini vurgulaması yönüyle hala faydalı bir analiz aracı olduğu söylenebilir. Oliver Boyd-Barrett (1998'den aktaran, Matos, 2012) de medya emperyalizmi tezini medyada artan küreselleşme sürecini dikkate alarak revize etmiş, ancak bu tezin ülkeler arasındaki eşitsizlikleri ve bu eşitsizliğin geniş kapsamlı politik ve ekonomik bağımlılığa yansımasını açıklamada hala değerli olduğunu vurgulamıştır.

\section{2. İyimser Yaklaşımlar 3.2.1. Yerelleştirme}

Küresel haber üretimi ve dağıtımının az sayıdaki uluslararası haber ajansının kontrolünde olmasının haberlerde tektipleşmeye ve giderek medya emperyalizmine yol açtığı iddiasına karşı çıkan araştırmacıların dayanaklarından biri yerelleştirme tezi olarak özetlenebilecek görüştür. "Küresel enformasyondaki özgün unsurları seçme ve yerel bir çerçeveye uyarlama süreci" (Clausen, 2003a: 14) şeklinde tanımlanan yerelleştirme kavramı, haberin küreselleşerek tektipleştiği tezine karşı çıkmakta, uluslararası haber ajanslarının farklı ülkelere dağıttığı dış haberlerin ülke okuruna uygun şekilde seçme, düzenleme ve tanımlama işlemlerinden geçirildiğini ve habere özgün ulusal nitelikler dâhil edilerek yerel okura sunulduğu savına dayanmaktadır.

Yerelleştirme kavramını haber araştırmalarına kazandıran Michael Gurevitch, Mark Levy ve Itzhak Roeh, bu kavramla, farklı haber servislerine ulaşan küresel haberin tektipleşmesinin zorunlu bir durum olmadığını ileri sürmüştür. Gurevitch ve arkadaşlarına (1991: 206-7) göre, yerelleştirme, haberin küreselleşmesine karşı dengeleyici bir güçtür ve aynı olayların farklı şekilde, farklı yerel izleyicilerin hassasiyetlerine ve sosyal ve politik çerçevelere uygun olarak haberleştirilmesi durumunda tektipleşme tehdidi mesnetsizdir.

Yerelleştirme tezinin savunucularından Clausen'e (2003a: 14, 110, 33) göre de, teknolojilerin evrensel nitelik kazanması ve dış haberlere uluslararası haber ajansları üzerinden ulaşılması nedeniyle haber programlarının içeriğinin benzer olduğu iddiası doğru değildir. Uluslararası haber iletimi hem "evrensel" hem de "yerel" unsurlar içermektedir. Evrensel unsurlar küresel formatları ve türsel uzlaşımları, yerel unsurlar ise ulusal medya kuruluşlarındaki kültürel temaları, aktörleri ve iletişim stratejilerini ifade etmektedir. Küresel haberlerin yerelleştirilme süreci makro ve mikro seviyelerde gerçekleşmektedir. Makro seviyede, bu haberler, tıpkı diğer enformasyon ürünleri gibi, hayali izleyicilerin bulunduğu yerel piyasalara uygun referans çerçeveleri içinde uyarlanıp sunulmaktadır. Mikro seviyede ise, haber metinlerindeki enformasyonun çerçeveleme ve ön plana çıkarma süreçleri zorunlu ve kaçınılmazdır. Metin ve görsellerin bu şekilde işlenmesi çeşitli "yerelleştirme" seviyeleri içerir. Buradaki soru, enformasyonun uyarlanıp uyarlanmadığı ve uyarlandıysa ne kadar uyarlandığıdır. Bu sorunun cevabı ne olursa olsun, yerli halkın ilgisini çekecek unsurlar katılan küresel haber artık yeni bir haberdir. Hem yerli hem de yabancı unsurlar içeren bu haber Nossek'e (2004: 346) göre "melez" bir haberdir. Melez haber, başka bir ülkedeki bir 
olay veya sorunu ele alabilir; fakat aynı haber, yayınlandığı ülkeyle doğrudan bağlantılı unsurlara da işaret ediyor olacaktır.

$\mathrm{Bu}$ noktada, küresel haber ajanslarından gelen haberlerin yerli medya kuruluşlarınca yerelleştirilmesinin küresel haberin tektipleşmesi ve medya emperyalizmi gibi kaygılara bir cevap olup olmadığ 1 sorusu ortaya çıkmaktadır. Gerçekten de, uluslararası haber ajanslarından gelen haberler yerel bir perspektif verilip yerel kültüre uyarlandığında tektipleşme tehlikesinden kurtulmakta midır? Paterson'un bu soruya cevabı olumsuzdur. Paterson, 1995 yılında televizyon haberleri üzerinde yaptığı iki günlük bir araştırma sonucunda, analiz edilen haberlerin önemli bir bölümünde ulusal yayıncıların müdahalesinin minimum düzeyde olduğunu tespit etmiştir. Ulusal yayıncıların haber ajanslarına yaptığı ödeme düşünüldüğünde, bu durum ekonomik olarak anlamlı görülebilir. Fakat aynı zamanda yerli medyanın bu haber kuruluşlarının editoryal değerlendirmelerine önemli ölçüde bağlı olmaları anlamına da gelmektedir. Dahası, yerel medya kuruluşunun editoryal müdahalesi olsa ve yerel medya kuruluşu küresel haber ajansından gelen haberlere kendi ülkesiyle ilgili bir bakış açısı getirse bile, müdahale edilen materyalin kaynağı yine az sayıdaki küresel haber ajansı olacaktır. Yalnızca haberin giriş cümlelerini değiştirerek veya habere özel bir stil getirerek haber içeriğinin temel mesajları değiştirilmiş olmaz, ayrıca neyin haber sayılacağına ilişkin seçimler de gerçekten değişmiş sayılmaz. Dolayısıyla, küresel haberlerin "yerelleştirildiği" iddiaları tartışmalıdır ve medya emperyalizmi tezine tam bir cevap olamaz (Arya, 2011: 17; MacGregor, 2013: 44; Paterson 2011: 33). Yerelleştirme tezi ise, Bat1 merkezli uluslararası haber sistemini idealleştirmek üzere kullanılan araçlardan biridir.

\subsubsection{Karşı akış yaklaşımı}

Haber üretim ve dağıtımının Batılı ülkelerin egemenliğinde olduğu tezine karşı, bazı araştırmacılar (örneğin, Hjarvard, 2001; Macgregor, 2013, Ritzer, 2010; Volkmer, 2007) Batı'dan Doğuya veya Kuzey'den Güney'e doğru tek yönlü akış olmadığını, haberin birçok yönde aktığını iddia etmiştir. Bu iddiaya göre, 1990'ların başından itibaren yeni uydu teknolojilerinin gelişmesiyle birlikte kitlelerin habere ulaşabileceği kanallar da çeşitlilik kazanmıştır. Artık, uluslararası büyük haber ajansları ve CNN, BBC World gibi güçlü çok uluslu şirketlerin yanı sıra, oldukça spesifik, küresel olarak yayılmış veya bölgesel izleyici topluluklarına yönelik küçük ve orta büyüklükte çok sayıda başka uluslararası haber kanalı da ortaya çıkmıştır. Aralarında Katar merkezli Al-Jazeera, Londra merkezli olduğu halde Arap göçmenlere yönelik yayın yapan MBC (the Middle-East Broadcasting Center), dünyanın birçok bölgesinde faaliyet gösteren Brezilya televizyon kanalı TV Globo International'ın da bulunduğu bu kanallar Batılı haber ajanslarının alternatifidir ve bir karşı akış oluşturmaktadır. Özellikle Al-Jazeera, Batılı küresel haber ajanslarının haber ekolojisindeki egemenliğini dengelemektedir.

Karşı akış kavramını Boyd-Barrett ve Thussu (1992'den aktaran Figenschou, 2014: 85), Batı1ı medya akışının egemenliğine karşı çıkan medya akışı olarak tarif etmiş, bu akışın ekonomik ve politik olarak daha güçsüz olandan güçlü olana, Güneyden Kuzeye doğru ve yatay olarak Güney-Güney arasında gerçekleştiğini söylemiştir. Thussu (2007'den aktaran Figenschou, 2014: 85), medya ürünlerinin dünya üzerindeki akışını üç kategorili bir tipoloji üzerinden açıklamıştır. Bu kategorilerin ilki Batılı medyanın egemenliğine dayanan küresel akışlardır. İkincisi, ticari bir ortamda faaliyet gösteren özel ve devlet destekli (Hindistan film endüstrisi Bollywood ve Latin Amerika telenovelalar gibi) ulus-ötesi akışlardır. Thussu'nun ikincil akışlar olarak ifade ettiği bu kategoride bulunan Al Jazeera, Telesûr, Russian Today ve CCTV-9 gibi ulus-ötesi akışlar bölgesel olarak önemli bir varlık göstermekte, fakat aynı zamanda kendi bölgeleri dışındaki izleyicileri de hedeflemektedir. Üçüncü kategori ise diaspora grupları gibi kültürel-dilsel spesifik izleyici gruplarını hedefleyen medya kanallarını 
içermektedir. Thussu'nun bu şekilde gruplandırdığ karşı akışların bir çoğu kendi üretim ülkelerindeki/bölgelerindeki egemen akışlar olup yalnızca başka bir yerdeki diaspora grupları ve genel izleyici tarafindan ulaşılabildiği zaman karşı akış haline gelmektedir.

Stig Hjarvard yaşanan süreci "bölgeselleştirme" olarak açıklamıştır. Hjarvard'a (2001: 27) göre, uydu televizyonun ilk yıllarında birçok kanal mümkün olduğunca geniş kitlelere seslenmeye çalışmıştır. CNN mümkün mertebe küresel olmaya çalışmış, Avrupa'daki birçok kanal da Avrupa'nın tamamını kapsama çabasına girmiştir. Fakat bu girişim başarısızlıkla sonuçlanınca son on yılın stratejisi programların bölgeselleştirilmesi, yani yerel çıkar ve ihtiyaçlara uydurulması olmuştur. Bölgeselleştirme sırasında bazı içerikler bölge için özel olarak üretilirken, bazıları da ana şirketin küresel hizmetlerinden uyarlanmıştır. Bölgeselleştirme küresel programlarda yaşanan dil problemlerini aşmanın da bir yolu olmuş, ulus ötesi haber servisleri sınırları ötesindeki farklı dil topluluklarına hitap edebilmiştir.

Karşı akış kavramı eksenindeki tartışmalar, Batılı haber ajanslarının küresel egemenliğinin sarsıldığına ve eski Batı merkezli küresel haber sistemi yapısının çok merkezli olmaya doğru kaydığına ilişkin iyimser görüşler için de dayanak oluşturmuştur. Özellikle Al Jazeera kanalının küresel haber sisteminin önemli aktörlerinden biri haline gelmesi Batıya meydan okuyan alternatif bir enformasyon akışı olarak görülmüş, yaşanan sürecin daha adil, heterojen, çoğulcu bir küresel haber sistemine geçişin işareti olduğu düşünülmüştür. Macgregor'un (2013: 57) sözleriyle ifade edilirse, yaşanan karşı akış artacak ve Batılı ajans haberlerinin Doğulu izleyici üzerindeki etkisini yumuşatacaktır. Gelişmekte olan ülkelerden gelen haber medyası ürünleri şu veya bu şekilde Batılı uluslararası haber ajanslarının konumuna meydan okuyabilir ve hatta belki bu konumu aşındırabilir.

Karşı akış kavramıyla ifade edilen bu iyimserliğe karşın, küresel haber sisteminde çoğulculaşmanın ve Batılı olmayan haber kanallarının Batılı pazarlara girmelerinin önünde yapısal engellerin devam ettiği de kabul edilmektedir (Rai ve Cottle, 2007: 72). Dahas1, Thussu'ya (2007: 35) göre, ikincil kategori kapsamındaki jeo-kültürel medya akışları dünyadaki iletişimin daha çeşitli ve demokratik hale geldiği yönünde yanlış bir izlenim verebilmektedir. Oysa Batılı olmayan birçok medya kuruluşunun küresel etkisi jeo-kültürel pazarlarla veya bölgesel ulus-üstü tüketicilerden oluşan küçük ceplerle sınırlıdır. Ayrıca, küresel akışlar, farklı izleyicilere yerelleştirilmiş medya içerikleri sunarak daha da güçlenmektedir. Amerika hegemonyasını genişletir ve derinleştirirken, melezleşmiş ve yerelleşmiş medya ürünleri küreselleşmenin daha kabul edilebilir bir yüzünü sunmakta ve dolayısıyla, serbest piyasa kapitalizminin ideolojik buyruklarını meşrulaştırmaktadır.

\subsubsection{Haber çeșitliliğinin artması}

İnternet, cep telefonu ve uydu gibi iletişim teknolojilerinde yaşanan gelişmeler alternatif haber kaynaklarının ortaya çıkmasına yol açmış ve uluslararası haber ajanslarını dış haberler için tek kaynak olmaktan çıkarmıştır. Bu süreçte haber aktörlerinin hemen hepsi kendi internet servislerini kurmuş, bu ise yerel medya kuruluşlarının haber kaynaklarına ulaşmasını kolaylaştırmıştır. Bu gelişmenin haber çeşitliliğinin artmasına bir katkısı da, Peter Berglez'in (2011: 150) ifadesiyle, yerel medya kuruluşlarının abone oldukları uluslararası haber ajanslarından gelen materyallerden bazılarının yerine yenilerini koyabilmesi, böylece enformasyonun homojenliğini azaltmasıdır. Yine farklı haber kuruluşlarının internet sitelerinin bulunması, özellikle dil engelini aşabilen okurlara aynı haberi dünyadaki farklı sitelerden okuyabilme imkânı sağlamıştır. Bazı haber servisleri ise çok dilli yayınlar üzerinden dil engelini aşmaya çalışmıştır.

Dijital teknolojilerin haberin çeşitlenmesine yaptığı en önemli katkılardan biri "yurttaş gazeteciliği" olarak adlandırılan gelişmedir. Teknolojik yöndeşme ve sosyal medya ağlarının 
ortaya çıkmasıyla birlikte, haber üretimi sıradan vatandaşları da kapsayacak şekilde genişlemiş, vatandaşlar çevrelerinde yaşanan olayları ellerindeki kamera veya cep telefonlarıyla haberleştirip anında geniş kitlelere yayma imkânı bulmuştur. Bu gelişme, elinde cep telefonu veya dijital kamera bulunan herkesin potansiyel bir muhabir haline gelmesine yol açmıştır. Vatandaşların topladıkları haber materyallerini doğrudan haber kuruluşlarına satabilmeleri, yurttaş gazeteciliğinin büyük haber ajanslarının otorite ve gücüne karşı bir alternatif oluştuğu yönünde iyimser bir yaklaşımı da beraberinde getirmiştir. $\mathrm{Bu}$ görüsse göre, vatandaşların kendi cep telefonu, kameraları, vs. ile topladıkları güncel haberler haber gündemini ve haber içeriklerini önemli ölçüde etkilemiş, bu ise sıradan vatandaşın katılımını sağlaması nedeniyle geleneksel gazeteciliğe nazaran daha demokratik bir haber toplama ve dağıtım sürecinin ortaya çıkmasına neden olmuştur.

Dijital teknolojilerin haber üretim ve dağıtımında çeşitliliğii, dahası yurttaş gazeteciliği durumunda demokratikleşmeyi getirdiği iddialarına karşın, yaşanan gelişmelerin yalnızca görüntüyü değiştirdiği ve haberde çeşitliliğin bir mit olmaktan öteye gidemediğine ilişkin eleştiriler de söz konusudur. Bu yaklaşıma göre, teknolojik gelişmeler sonucunda okurlar dünyanın her yerinden haber sitelerine anında ulaşsa da, önce tüketicinin bu sitelerin varlığını bilmesi gerekir. Bu da haber ve medya hizmetlerinde markanın önemini artırmış, hatta internette tam bir "markalar savaşı" yaşanmasına neden olmuştur. Markalar savaşının avantajlı tarafı ise çoğu durumda uluslararası haber ajansı etiketli haberleri veren büyük medya kuruluşları olmaktadır. Yine, dijital gelişmeler sonucunda haber dolaşımının hızlanması haber toplama süresini kısaltmış, bu da medya kuruluşlarının haber ajanslarından alınan malzemeye bağımlılığını artırmıştır. Başta uluslararası haberlerde olmak üzere birçok haberde ajans materyaline dayanılmaktadır. Yahoo gibi portallar kaynak çeşitliliğini iddia etse de, haber içeriklerini temin eden az sayıdaki aynı haber ajansına aşırı bağımlıdır ve ajanslardan gelen haber içeriklerini çok az değiştirmekte, genellikle değiştirmeden kullanmaktadır. Haberde çeşitlilik miti ise haberlerin tektipleşmesini ve dünya çapındaki orijinal haberleştirme miktarındaki azalmayı saklamaktan öteye gitmemektedir (Archetti, 2013: 422; Hjarvard, 2001: 29; Paterson 2006, 2011'den aktaran MacGregor, 2013: 56-7). Dolayısıyla, dijital teknolojilerin gelişimiyle haberin çeşitlenmesi arasında nedensellik ilişkisi kurulması anlamlı değildir ve küresel haber sistemindeki dengesizlikleri göz ardı etme riski taşımaktadır.

\section{Sonuç}

Uluslararası haber üretim ve dağıtımının kontrolü, dünya kamuoyunun ilgileneceği konuların, haberlerde ön plana çıkacak unsurların, bir ülkenin baskın imajının, dolayısıyla o ülkeye yönelik tutumun belirlenmesinde önemli rol oynamaktadır. Haberin küreselleşme sürecinin yaklaşık 150 yıl öncesine dayandığı ve bu süre boyunca haber akışında Batı merkezli uluslararası haber ajansları lehine bir dengesizliğin yaşandığı düşünüldüğünde, küresel haber sisteminin çoğulculuktan uzak yapısının ülkeler arasındaki asimetrik güç ilişkilerini pekiştirdiği yönündeki endişeler haklılık kazanmaktadır.

Uluslararası iletişim çalışmalarında küresel haber sistemindeki dengesizliklere ilişkin endişeleri dile getiren çok sayıda çalışma yapılmıştır. Bu çalışmalarda altı çizilen hususlardan biri, uluslararası haber ajanslarının da ulusal aidiyetlerinin olduğu ve kendi ulusal çıkarlarından bağımsız davranmalarının beklenemeyeceği, dolayısıyla, uluslararası kamuoyunun az sayıdaki Batılı haber ajansının ulusal çıkarları doğrultusunda yönlendirildiğidir. Mevcut sisteme yönelik bir diğer eleştiri de uluslararası haberlerde Batılı ülkelerin çıkarlarına öncelik tanıyacak şekilde tektipleşme yaşandığı, uluslararası haber gündeminin yine az sayıdaki uluslararası haber ajansı tarafından belirlendiği, bu dengesizliklerin ise ülkeler arasındaki asimetrik güç ilişkilerini pekiştirerek medya 
emperyalizmi tezini haklı çıkardığ haberlerin tektipleştiği iddiasının doğru olmadığı, zira uluslararası haber ajanslarından alınan haberlerin yerel medya kuruluşları tarafindan yerelleştirme sürecine tabi tutulduğu, dijital teknolojiler sayesinde hem haber tüketicisinin haber seçeneklerinin arttığı, hem de sokaktaki insanın olayları haberleştirip internet üzerinden dünyaya yayabildiği, bunun da haberi özgürleştirdiği yönünde görüşler mevcuttur. Bölgesel perspektiflerin yansitılmasına imkân veren Al Jazeera gibi alternatif medya kuruluşlarının varlığı da tektipleşme eleştirilerine karşı bir dayanak olarak sunulmaktadır.

Çalışmada aktarılan eleştirel ve iyimser görüşlerin tümü bir bütün olarak küresel haber sisteminin farklı boyutlarına işaret etmektedir. Ancak, uluslararası haber ajanslarının hala dünya haber trafiğinin ortalama yüzde 80'ini yönlendirdiği (Özmen, 2013: 137) ve haber içeriklerinin Avustralya'da \%65'inin, İngiltere'de \%70'inin ve Almanya'da \%80'e kadar olan kısmının ajanstan gelen haberin kopyası olduğu, özellikle internet gazetelerindeki son dakika haberlerinin \%80-90'ının haber ajansından geldiği haliyle ve herhangi bir değişiklik yapılmadan kullanıldığı (Matthews, 2013: 246) düşünüldüğünde, mevcut küresel haber sistemine ilişkin iyimserliğe kapılmak için henüz erken olduğu görülmektedir. Zira karş1 akışın varlığına rağmen, haber akışı hala büyük ölçüde Batılı küresel haber ajanslarının kontrolündeyse, dünya kamuoyuna akan haberlerin o ajansların bakış açısından bağımsız olduğu söylenemez. Uluslararası haber ajanslarından gelen haberler yerelleştirme işlemine tabi tutulsa da, haber materyalinin kaynağ 1 aynı olduğu sürece editoryal müdahale sınırlı olacak ve uluslararası haber gündemi o haber ajansları tarafindan belirlenmeye devam edecektir.

Haberin küreselleşme süreci, genel olarak küreselleşme sürecinin bir parçası sayılabilir. Küreselleşme süreciyse dünya toplumlarının birbiriyle bütünleşmesini, farklı kültürlerin birbirine açılmasını ve birbirinden eskisinden daha fazla haberdar olmasını gerektirir. Birbiri hakkında daha fazla bilgi sahibi olan toplumların birbirini anlaması ve karşılıklı diyalog geliştirmesi de daha kolay olacaktır. Ancak, ülkeler arasındaki tanıma, haberdar olma, bilme süreçlerinin tek yönlü olduğu bir sistemde çoğulcu, demokratik ve dengeli ilişkilerin kurulmasının zor olacağı açıktır. 


\section{KAYNAKÇA}

ARCHETTI, C. (2008). News Coverage of $9 / 11$ and the Demise of the Media Flows, Globalization and Localization Hypotheses. International Communication Gazette, 70(6), 463-495.

ARCHETTI, C. (2013). Journalism in the Age of Globalization: The Evolving Practices of Foreign Correspondents in London. Journalism: Theory, Practice and Criticism, 14(3), 419-436.

ARYA, K. (2011). The Over-Dependence of Indian English Newspapers on Global News Agencies for International News (Doctoral dissertation, Institute of Communication Studies, University of Leeds).

BERGLEZ, P. (2011). Global Journalism: An Emerging News Style and Outline for a Training Programme. In B. Franklin \& D. Mensing (Eds.), Journalism Education, Training and Employment (pp. 143-154). London, UK: SAGE Publications.

CARLSSON, U. (2003). The Rise and Fall of NWICO: From a Vision of International Regulation to a Reality of Multilevel Governance. Nordicom Review, 24(2), 31-67.

CHRISTIN, A. (2016). Is Journalism a Transnational Field? Asymmetrical Relations and Symbolic Domination in Online News. The Sociological Review, 64(2), 212-234.

CLAUSEN, L. (2003a). Global News Production. Copenhagen: Copenhagen Business School.

CLAUSEN, L. (2003b). Global News Communication Strategies: 9.11 .2002 around the World. Nordicom Review, 24(2), 105-115.

CLAUSEN, L. (2010). International News Flow. In S. Allan (Ed.), The Routledge Companion to News and Journalism (pp. 127-136). Oxon \& New York: Routledge.

DE BEER, A. S. (2010). News From and in the "Dark Continent" Afro-pessimism, News Flows, Global Journalism and Media Regimes. Journalism Studies, 11(4), 596 -609.

FIGENSCHOU, T. U. (2014). Al Jazeera and the Global Media Landscape: The South Is Talking Back. New York: Routledge.

GUREVITCH, M., M.R. LEVY ve I. ROEH (1991). The Global Newsroom: Convergences and Diversities in the Globalization of Television News. In P. Dahlgren \& C. Sparks (Eds.). Communication and Citizenship (195-216). London: Routledge.

HERBERT, J. (2001). Practising Global Journalism: Exploring Reporting Issues Worldwide. Oxford: Focal.

HERMAN, E. S.ve McCHESNEY, R. W. (2004). The Global Media - the New Missionaries of Corporate Capitalism. London: Continuum.

HJARVARD, S (2001). News Media and the Globalization of the Public Sphere In S. Hjarvard (Ed.), News in a Globalized World (17-39). Göteborg: Nordicom.

MACGREGOR, P. (2013). International News Agencies: Global Eyes that Never Blink. In K. Fowler-Watt, \& S. Allan, (Eds.) Journalism: New Challenges (3563). Bournemouth: Bournemouth University, Centre for Journalism \& Communication Research.

MAGDER, T. (2003). Watching What We Say: Global Communication in a Time of Fear. In 
D. Thussu \& D. Freedman (Eds.), War and the Media (28-44). London: Sage.

MATOS, C. (2012). Globalization and the Mass Media. In G. Ritzer. (Ed.). Encyclopedia of Globalization. Oxford: Wiley-Blackwell.

MATTElART, A. (1994). Mapping World Communication: War, Progress, Culture. (S. Emanuel \& J. A. Cohen, Trans.). Minneapolis: University of Minnesota Press.

MATTHEWS, J. (2013). Journalists and Their Sources: The Twin Challenges of Diversity and Verification. In K. Fowler-Watt, \& S. Allan, (Eds.) Journalism: New Challenges (242-58). Bournemouth: Bournemouth University, Centre for Journalism \& Communication Research.

McPHAIL, T. (2006). Global Communication: Theories, Stakeholders, and Trends ( $2^{\text {nd }}$ ed.). Malden: Willey Blackwell.

McQUAIL, D. (2010). McQuail's Mass Communication Theory (6 $6^{\text {th }}$ ed.) Los Angeles: Sage.

MUSA, M. (1990). News Agencies, Transnationalization and the New Order. Media, Culture and Society, 12, 325-342.

NOSSEK, H. (2004). Our News and their News: The Role of National Identity in the Coverage of Foreign News. Journalism, 5(3), 343-368.

ÖZMEN, Ş. Y. (2013). Küresel Haber Ağları. Orhon, E. N. ve Y. B. İşçibaş1 (Ed.). Uluslararası Illetişim içinde, Eskişehir: Anadolu Üniversitesi Yayınları.

ÖZTÜRK, K. (2013). Uluslararası Habercilik. A. M. Vural (Ed.). Haber Türleri içinde. Eskişehir: Anadolu Üniversitesi Açık Öğretim Yayınları.

PATERSON, C. (2001). Media Imperialism Revisited: The Global Public Sphere and the News Agency Agenda. In S. Hjarvard (Ed.). News in a Globalized Society (pp. 77-92). Göteborg: Nordicom.

PATERSON, C. (2007). International News on the Internet: Why More is Less. Ethical Space: The International Journal of Communication Ethics, 4 (1), 57-66.

PATERSON, C. (2011). The International Television News Agencies The World From London New York: Peter Lang.

RAFEEQ, A. (2007). Covering Conflicts: The Coverage of Iraq War II by the New Zealand Herald, the Dominion Post, and the Press (Doctoral Dissertation, University of Canterbury).

RAI, M. \& COTTLE: (2007). Global Mediations: On the Changing Ecology of Satellite Television News, Global Media and Communication, 3(1), 51-78.

RITZER, G. (2010). Küresel Dünya (M. Pekdemir, Çev.). İstanbul: Ayrıntı.

ROSENTHAL, C. (2015). Reconsidering Agenda Setting and Intermedia Agenda Setting from a Global Perspective: A Cross-National Comparative Agenda Setting Test (MSc Thesis, the Department of Media and Communications, London School of Economics and Political Science).

RYABINSKA, N. (2012). "International News Production in Post-Soviet Ukraine: Where is the 'Center'?" Global Media Journal 2(2): 1-21.

SCHILLER, H. (1991). Not Yet the Post-Imperialist Era. Critical Studies in Mass 
Communication, 8(1), 13-28.

SPARKS, C. (2007). Globalization, Development and the Mass Media. London: Sage.

THOMPSON, J. B. (2008). Medya ve Modernite. (S. Öztürk, Çev.). İstanbul: Kırmızı Yayınları. Orijinal Çalışma Basım Tarihi: 2004.

THUSSU, D. K. (2002). International Communication: Continuity and Change ( $2^{\text {nd }}$ ed.). London: Hodder Arnold.

THUSSU, D. K. (2007). Media on the Move: Global Flow and Contra-flow. New York: Routledge.

UNITED NATIONS EDUCATIONAL, SCIENTIFIC AND CULTURAL ORGANIZATION. (1980). Many Voices, One World. New York: Kogan Page Ltd.

VAN ELTEREN, M. (2014). Reconceptualizing "Cultural Imperialism” in the Current Era of Globalization. In R. S. Fortner \& P. M. Fackler (Eds). International Handbook of Media and Mass Communication Theory, Vol. 1 (pp. 400-419). Malden: Wiley Blackwell.

VOLKMER, I. (2007). Spheres of Influence and Challenges to Global Media Policy. International Journal of Communication, 1, 56-73.

WANTA, W., GOLAN, G. ve LEE, C. (2004). Agenda-setting and International News: Media Influence on Public Perceptions of Foreign Nations. Journalism and Mass Communication Quarterly, 81(2), 364-377.

WATANEBE, K. (2012). Modeling the Global News Flows. Erişim tarihi: 15.08.2017, http://koheiw.net/wp-content/uploads/2014/09/Global-ageda-setting-11-blog.pdf. 